\title{
Commentary: Thoracic research funding: Staying power is only one issue
}

\author{
Harvey I. Pass, MD
}

Who would have guessed? In an incredibly eye-opening article, ${ }^{1}$ we learn that over the last almost 40 years, $16 \%$ of general thoracic surgeons have been funded by the National Institutes of Health with a total of 136 grants if you consider the top quartile of centers in the country received National Institutes of Health funding. The profile of these individuals is simple: male, older, and mainly associate or full professors and division or section chiefs, and it certainly helps if you have a $\mathrm{PhD}$. The majority of the awards are R01s, and along the way, junior, mentored awards have been translated to R01s. Nevertheless, what happens to funded investigators over time? Why is it that $82 \%$ of the R01s are not renewed? Is it burnout? Is it that grant funding leads to early academic promotion and possibly tenure, and the grantee coasts? Does the grantee get pressure to maintain clinical revenue while trying to manage 1 or more grants?

As great as the article is, it signals some warnings when taken into context with how academic programs are changing. Programs like the I-6, 4-3 programs, and specific thoracic tracts are all trying to concentrate specialty thoracic and cardiac training for more concentrated but shorter experiences. How is this going to influence the potential crop of future investigators?

The article mentions 3 T-32 training programs. Are they specifically for general thoracic surgery? Frankly, we do not have enough of these, and I will specifically say that we need more that are concentrated on the rapidly changing therapies that influence general thoracic surgeons in thoracic oncology. And by the way, it's great that 63 of the 136 grants were thoracic

From the Division of General Thoracic Surgery, Department of Cardiothoracic Surgery, NYU Langone Medical Center, New York, NY.

Disclosures: The author reported no conflicts of interest.

The Journal policy requires editors and reviewers to disclose conflicts of interest and to decline handling or reviewing manuscripts for which they may have a conflict of interest. The editors and reviewers of this article have no conflicts of interest.

Received for publication Feb 6, 2021; revisions received Feb 6, 2021; accepted for publication Feb 8, 2021; available ahead of print Feb 19, 2021.

Address for reprints: Harvey I. Pass, MD, Division of General Thoracic Surgery, Department of Cardiothoracic Surgery, NYU Langone Medical Center, 530 First Ave, 9V, New York, NY 10016 (E-mail: Harvey.Pass@ nyumc.org).

J Thorac Cardiovasc Surg 2022;163:880-1

$0022-5223 / \$ 36.00$

Copyright (C) 2021 by The American Association for Thoracic Surgery

http://dx.doi.org/10.1016/j.jtcvs.2021.02.050

oncology, but how about the distribution of higher-level mature grants compared with transplant, benign, and other?

I think we are selling ourselves short and can do better. Who are these people who have sustained grant funding? How did they do it? What were the barriers? How did they overcome them? They should be keynote educators at the Annual Meeting in the mentorship forums, not just the young investigators who received their first grants. Its staying power is difficult: Does the passion wither? Was the passion ever truly there?

We also are going to need to do better about presenting opportunities to all interested potential young resident researchers. Maybe we need to have an ongoing section in our journals listing the investigators with general thoracic base grants so these people do not get lost in the wilderness or feel that they can only work at their own institution. Maybe programs should go back to the dark ages and use a departmental tax to provide "in the department" funds for research expansion for the mentoring of prospective researchers. Department chairs need to realize the R01s do not just happen: They require significant preaward capital. It would be interesting to know how funds for this are distributed at the "meccas" with regard to thoracic versus cardiac-type dedicated departmental research funding.

I do not have the answers. I only know that I have lived through this, and the article highlights many issues, both good and worrisome, that even after 39 years of running a 
laboratory I have not been able to deal with. Let us get together to increase the supply not only over successful but also long-term investigators to satisfy the demands for novel research in thoracic surgery.

\section{Reference}

1. Narahari AK, Mehaffey JH, Chandrabhatla AS, Hawkins RB, Charles EJ, Roeser ME, et al. Longitudinal analysis of National Institutes of Health funding for academic thoracic surgeons. J Thorac Cardiovasc Surg. 2022;163: 872-9.e2.
See Article page 872 .

\section{Commentary: For thoracic}

\section{surgeons, a strategic approach to the funding game}

\author{
Tony E. Godfrey, $\mathrm{PhD},{ }^{\mathrm{a}}$ and Virginia R. Litle, $\mathrm{MD}^{\mathrm{b}}$
}

In this educational manuscript from the American Association for Thoracic Surgery's 2020 annual meeting, Narahari and colleagues ${ }^{1}$ hypothesize that thoracic surgeons have difficulty obtaining National Institutes of Health (NIH) funding in a challenging climate. However, they conclude that they are actually doing well by most of their metrics. The question then becomes how can thoracic surgeons do better?

First, we ask what is the value of NIH funding aside from research money? Faster promotions, appreciation from academic leadership, respect from peers. Most importantly, though, for surgeons it is the opportunity to benefit patients by addressing the hypotheses that arise during clinical care.

What can we do to optimize the number of thoracic surgeons pursuing and obtaining NIH funding, and what are the best backup plans? The holy grail of funding is the R01 grant, but we shouldn't knock the increasing number of opportunities from professional and private foundations, the Department of Defense, and industry.

Narahari and colleagues found that only 16\% (63 of 395) of the thoracic surgeons surveyed were funded at any point during their career. We do not know the applicant denominator, but regardless, 63 in 39 years is actually quite low. The barriers

\footnotetext{
From the ${ }^{\mathrm{a} D e p a r t m e n t}$ of Surgery and ${ }^{\mathrm{b}}$ Division of Thoracic Surgery, Boston University School of Medicine, Boston, Mass.

Disclosures: The authors reported no conflicts of interest.

The Journal policy requires editors and reviewers to disclose conflicts of interest and to decline handling or reviewing manuscripts for which they may have a conflict of interest. The editors and reviewers of this article have no conflicts of interest.

Received for publication March 3, 2021; revisions received March 3, 2021; accepted for publication March 3, 2021; available ahead of print March 10, 2021.

Address for reprints: Virginia R. Litle, MD, Division of Thoracic Surgery, Department of Surgery, Boston University, 88 East Newton St, Collamore 7380, Boston, MA 02118 (E-mail: Virginia.litle@bmc.org).

J Thorac Cardiovasc Surg 2022;163:881-2

$0022-5223 / \$ 36.00$

Copyright (c) 2021 by The American Association for Thoracic Surgery

http://dx.doi.org/10.1016/j.jtcvs.2021.03.009
}

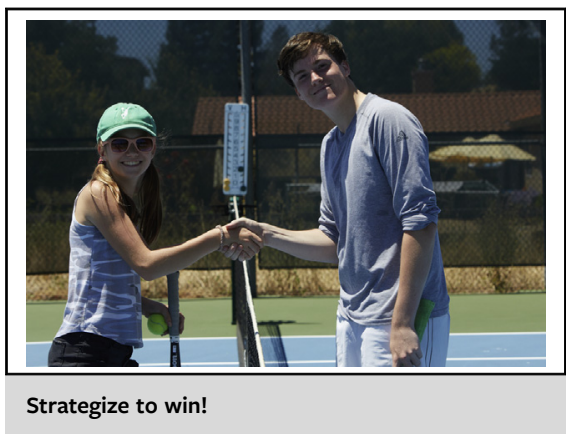

\begin{abstract}
CENTRAL MESSAGE
With collaboration, mentorship, and time to think, thoracic surgeons can win the National Institutes of Health funding game, and more will want to play.
\end{abstract}

to funding are familiar: clinical demands, protected research time, the gap between surgeon salaries and the NIH salary cap. The authors make suggestions, including implementation of transitional awards for clinicians similar to F99/K00 awards for basic scientists and modifying eligibility criteria for K99/ R00 awards. But we don't want to rob from Peter to pay Paul: If scientists don't get funding, they're out of a job.

Academic medical institutions, department leaders, and the NIH all need to address these issues if surgeons are to be encouraged to play and be winners. No more blame game, though. Investigators must look within as well. How can they submit the best proposal so that it gets discussed and ranked well by the study section? Suggestions include (1) secure good mentorship; (2) dedicate a realistic amount of time to grant preparation; (3) commit the appropriate effort to the grant ${ }^{2,3}$ (a principal investigator [PI] requesting only $5 \%$ to $10 \%$ effort on a big study will be of concern to 